\title{
Magnesium Isoglycyrrhizinate Alleviates Arsenic Trioxide-Induced Cardiotoxicity: Contribution of Nrf2 and TLR4/NF-kB Signaling Pathway
}

This article was published in the following Dove Press journal: Drug Design, Development and Therapy

\author{
Bin Zheng ${ }^{1, *}$ \\ Yakun Yang ${ }^{1} *$ \\ Jinghan $\mathrm{Li}^{\prime}$ \\ Jing $\mathrm{Li}^{1}$ \\ Saijie Zuo' \\ $\mathrm{XiChu}{ }^{2}$ \\ Shan $\mathrm{Xu}^{3}$ \\ Donglai Ma (D) ${ }^{1}$ \\ Li Chu ${ }^{1,4}$
}

'School of Pharmacy, Hebei University of Chinese Medicine, Shijiazhuang, Hebei, 050200, People's Republic of China; ${ }^{2}$ Department of Pharmacy, The Fourth Hospital of Hebei Medical University, Shijiazhuang, Hebei, 0500I I, People's Republic of China; ${ }^{3} \mathrm{Hebei}$ Province Hospital of Chinese Medicine, Affiliated Hospital of Hebei University of Chinese Medicine, Shijiazhuang, Hebei, 050200, People's Republic of China; ${ }^{4} \mathrm{Hebei}$ Key Laboratory of Integrative Medicine on Liver-Kidney Patterns, Hebei University of Chinese Medicine, Shijiazhuang, Hebei, 050200, People's Republic of China

*These authors contributed equally to this work
Correspondence: Donglai Ma; Li Chu School of Pharmacy, Hebei University of Chinese Medicine, Shijiazhuang, Hebei, 050200, People's Republic of China $\mathrm{Tel} / \mathrm{Fax}+86$ 3II 899267/9 Email mdl_hebei@aliyun.com; chuli06I4@I26.com
Purpose: Magnesium isoglycyrrhizinate ( $\mathrm{MgIG})$, a single stereoisomer magnesium salt of glycyrrhizic acid, has beneficial effects on the cardiovascular system through antiinflammatory, anti-oxidation, and anti-apoptotic actions. However, MgIG has not been shown to provide protection against cardiotoxicity induced by arsenic trioxide (ATO). This study aims to demonstrate the protection of MgIG against ATO-induced cardiac toxicity in mice and to investigate the underlying mechanism.

Methods: A mouse cardiotoxicity model was established by administering $5 \mathrm{mg} / \mathrm{kg}$ ATO for 7 days. MgIG used in conjunction with the ATO to assess its cardioprotection.

Results: MgIG administration could significantly reduce reactive oxygen species generation and the changes in tissue morphology. Also, MgIG administration increased the activity of antioxidase, such as superoxide dismutase, catalase, and glutathione peroxidase, and reduced malondialdehyde content and pro-inflammatory cytokine levels. Western blotting showed decreased expression of Bcl-2 associated X protein and Caspase-3, with increased expression of B-cell lymphoma 2. Importantly, MgIG administration increased nuclear factor-erythroid -2-related factor 2 (Nrf2) expression, while the expressions of nuclear factor kappa-B (NF$\kappa \mathrm{B})$ and toll-like receptor-4 (TLR4) were significantly decreased.

Conclusion: Our data showed that MgIG alleviates ATO-induced cardiotoxicity, which is associated to the anti-inflammation, anti-oxidation, and anti-apoptosis action, potentially through activation of the Nrf2 pathway and suppression of the TLR4/NF- $\kappa B$ pathway.

Keywords: magnesium isoglycyrrhizinate, arsenic trioxide, cardiotoxicity, Nrf2, TLR4/ $\mathrm{NF}-\kappa \mathrm{B}$

\section{Introduction}

Arsenic is a ubiquitous and well-proven carcinogenic metal that is widely distributed in air, water, and soil. ${ }^{1,2}$ People are exposed to arsenic through inhalation, ingestion, skin contact, and parenteral routes, which can influence health, including cardiovascular and peripheral vascular disease. ${ }^{3}$ However, arsenic trioxide (ATO), the main component of arsenic in nature, has been used as a drug for more than 2400 years, and can be used to treat infectious diseases and cancer, especially in acute promyelocytic leukaemia nowadays (APL). ${ }^{4,5}$ Unfortunately, cardiotoxic and hepatotoxic side effects have been noted for ATO. ${ }^{6}$ So far, clinical and pharmacological attempts to reduce the adverse effects of arsenic have had little success. Because of these limitations, many patients are precluded from receiving effective treatments. 
Studies have shown that inflammation, oxidative stress, and apoptosis are the potential mechanisms of cardiotoxicity caused by ATO. ${ }^{7,8}$ Proverbially, oxidative stress injury is the basic pathogenesis of cardiovascular anomalies in different types of cardiovascular diseases. ${ }^{9}$ Hughes et al have indicated that oxidative stress can be inhibited by activating antioxidase through nuclear factor-erythroid-2-related factor 2 (Nrf2). ${ }^{10}$ Exposure to arsenic could cause an excess of reactive oxygen species (ROS) produced by the body, which would damage a variety of cellular macromolecules, including DNA, lipids, and proteins. ${ }^{11-13}$ The opening and closing of Nrf2 could protect cells from free radical injury and apoptosis, thereby promoting cell survival. ${ }^{14}$ Therefore, anti-oxidative drugs might alleviate ATO-induced cardiotoxicity. A recent study has shown that the anti-oxidant Salvianolic acid B can alleviate ATO-induced cardiotoxicity by reducing oxidative stress injury. ${ }^{15}$ Moreover, inflammatory factors and oxidative stress, which are tightly linked, are characteristics of cardiac diseases. ${ }^{16}$ Given the connection between innate and acquired immunity, toll-like receptor-4 (TLR4) could activate the intercellular nuclear factor kappa-B (NF-KB) pathway. The TLR4/ $\mathrm{NF}-\mathrm{kB}$ signalling pathway is a significant pathway associated with the inflammatory response. ${ }^{17,18}$ Apoptosis has recently been linked to arrhythmia and other diseases of the conduction system. ${ }^{19,20}$ Using in vivo and in vitro approaches, Zhao et al have demonstrated that necrosis and apoptosis are involved in ATO-induced cardiac toxicity. ${ }^{21}$ Therefore, inhibition of myocardial cell apoptosis could prevent or reduce ATO-induced cardiotoxicity.

Liquorice (Glycyrrhizauralensis, Fisch), a traditional herb, is native to Southern Europe and East Asia, previous reports have shown that Liquorice has multiple pharmacological activities. ${ }^{2-24}$ Glycyrrhizic acid, an active ingredient extracted from liquorice, has been shown to provide protection on myocardial injury and the protection on liver and kidney damage caused by anti-cancer drugs. ${ }^{25}$ Magnesium isoglycyrrhizinate (MgIG, Figure 1) is the fourth-generation glycyrrhizic acid preparation. ${ }^{26} \mathrm{~A}$ large number of reports indicate that MgIG has a variety of biological activities, such as anti-inflammatory, antioxidant, anti-apoptotic, and anti-cancer actions. ${ }^{27-29}$

Previous studies have reported that MgIG has strong myocardial protections, including anti-myocardial fibrosis, antimyocardial ischemia (MI), and infarction. ${ }^{30,31}$ Among them, Ma et al demonstrated that MgIG could reduce myocardial fibrosis in mice induced by isoproterenol (ISO), and the protective effects might be relevant to the decreased expression levels of NF-kB. ${ }^{30}$ Zhao et al have demonstrated that monoammonium glycyrrhizinate, an aglycone of glycyrrhizin that can be extracted from liquorice, provides protection against ISO-induced MI damage (in vivo and in vitro). ${ }^{31}$ Furthermore, we found that MgIG can reduce the concentration of intracellular calcium ions and the contractility of myocardial cells by inhibiting the L-type calcium current of myocardial cells, which has a similar effect to calcium antagonists. ${ }^{32}$ However, to our knowledge, no study has explored the protection offered by MgIG in ATO-induced cardiotoxicity or the underlying mechanism.

Because of these findings, we hypothesize that $\mathrm{MgIG}$ can protect against cardiotoxicity caused by ATO. In the present study, the cardioprotection of MgIG was studied by assessing the morphological and biochemical changes in the cardiotoxicity model. Furthermore, the underlying mechanisms of MgIG against inflammation, oxidative stress, and apoptosis were explored through activating the Nrf2 and suppressing the TLR4/NF- $\mathrm{KB}$ signalling pathway. Our research presents novel insights into the protective effects of MgIG and provides a new strategy for treating cardiotoxicity caused by ATO.

\section{Materials and Methods}

\section{Animals}

Male kunming mice $(22.0 \pm 2.0 \mathrm{~g})$ were given from the Laboratory Animal Center of Hebei Medical University. The mice were given a normal granular diet and drinking water, and maintained at $50 \pm 10 \%$ relative humidity and $25 \pm 2{ }^{\circ} \mathrm{C}$, with a $12 \mathrm{~h} \mathrm{light/dark} \mathrm{cycle.} \mathrm{All} \mathrm{experimental}$ and animal handling procedures were approved by the Ethics Committee for Animal Experiments of Hebei University of Chinese Medicine (DWLL2020005) and conformed to the National Institutes of Health Guidelines for the Care and Use of Laboratory Animals.

\section{Reagents}

MgIG injection was purchased from the Chia Tai Tianqing Company (Nanjing, China). ATO was provided by Beijing Shuanglu Company (Beijing, China). All other analytical grade reagents purchased from Sigma Chemical Company (St. Louis, MO, USA).

\section{Experimental Design}

Fifty mice were assigned to five experimental groups $(\mathrm{n}=$ 10) at random:

(1) Control group (CONT, normal saline, $10 \mathrm{mg} / \mathrm{kg} / \mathrm{d}$ ).

(2) ATO treatment group (ATO, $5 \mathrm{mg} / \mathrm{kg} / \mathrm{d}$ ). 


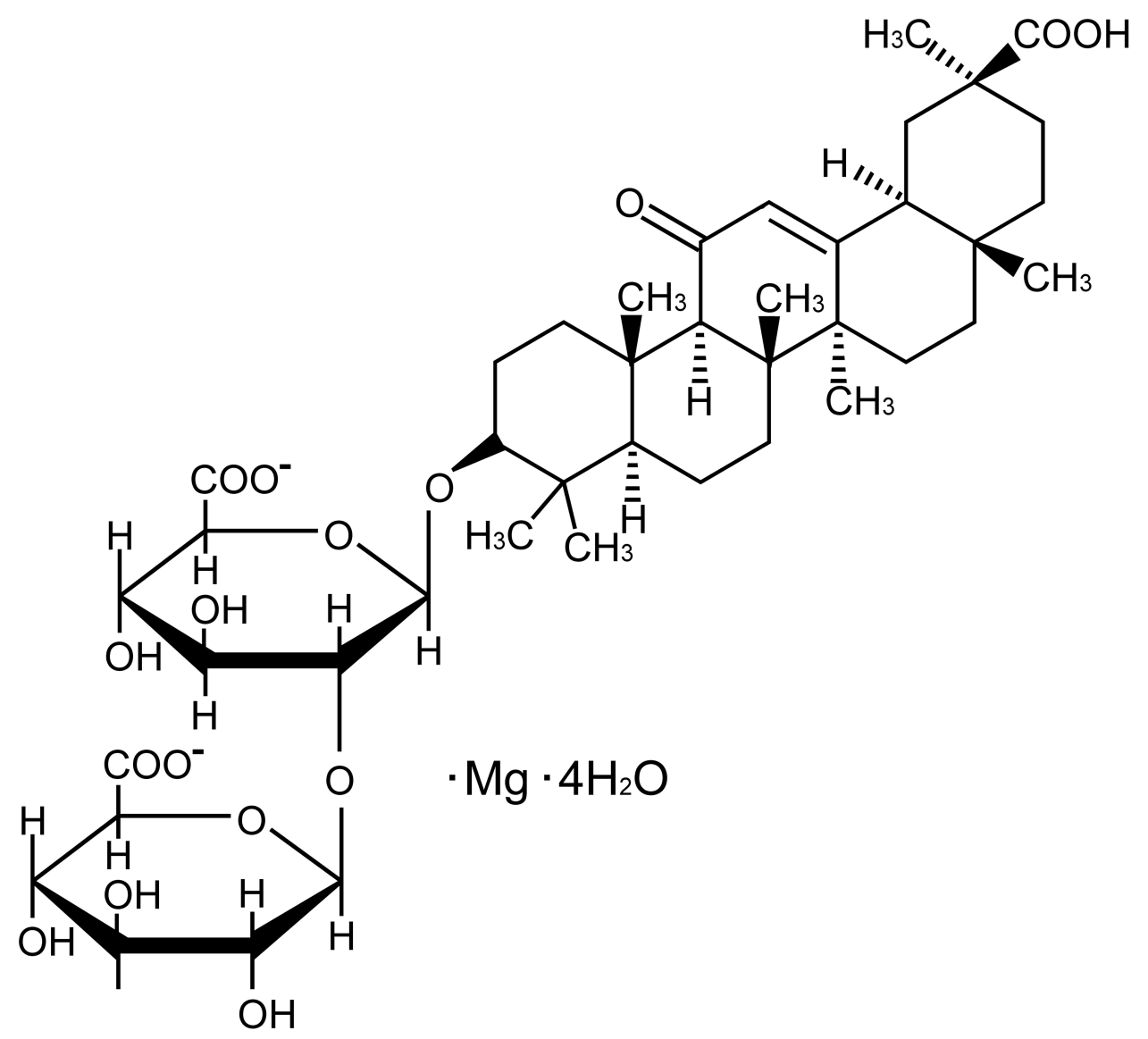

Figure I Chemical structure formula of MgIG.

(3) MgIG alone treatment group (MgIG, $50 \mathrm{mg} / \mathrm{kg} / \mathrm{d}$ ).

(4) High-MgIG + ATO treatment group (H-MgIG, $50 \mathrm{mg} / \mathrm{kg} / \mathrm{d})$.

(5) Low-MgIG + ATO treatment group (L-MgIG, $25 \mathrm{mg} / \mathrm{kg} / \mathrm{d}$ ).

All mice were administered by intraperitoneal injection in this experiment. Except for the CONT group and the MgIG alone group, ATO was intraperitoneally injected daily for 7 consecutive days. After 7 days, pentobarbital sodium $(50 \mathrm{mg} / \mathrm{kg})$ was used to anesthesia all mice. Blood was drawn from the eyeball and centrifuged at $1500 \mathrm{rpm}$. After centrifugation, the serum was collected and stored at $-20{ }^{\circ} \mathrm{C}$. Then, the heart tissues were quickly removed, some of which were put into a paraformaldehyde solution with a volume fraction of 0.04 . The other part was put into liquid nitrogen, and then transferred to the refrigerator at $-80{ }^{\circ} \mathrm{C}$ for preservation.

\section{Histopathological Analysis}

The mouse heart tissue samples were cut into two parts, trimmed and fixed with 10\% neutral buffered formalin fixative, and embedded in conventional paraffin. The specimens were cut into 4- $\mu \mathrm{m}$ thick sections and stained with hematoxylin-eosin (H\&E). The results were viewed through the light microscope $(400 \times)$. We randomly selected six high-power fields per slice, and used Image-Pro Plus software to measure the positive signals of myocardial injury in selected fields-of-view. Then, we calculated the percentage of positive signal staining area in the entire field-of-view.

\section{Assessment of Serum Biochemical Analysis}

We collected whole blood samples and separate them at $1500 \mathrm{rpm}$ for $10 \mathrm{~min}$, then drawing supernatant into Doff tubes. We stored the serum in the refrigerator at $-20^{\circ} \mathrm{C}$ for later use. Biochemical tests of the serum were carried out within 2 days. The activities of creatine kinase (CK, Catalog: A032-1-1), lactate dehydrogenase (LDH, Catalog: A2020-2-2), malondialdehyde (MDA, Catalog: A003-1-1), superoxide dismutase (SOD, Catalog: A0013-2), glutathione peroxidase (GSH-Px, Catalog: A0051-2), and catalase (CAT, Catalog: A007-1-1) in the serum 
were detected by colorimetric assay using commercial kits. All kits used for serum biochemical analysis were purchased from Jiancheng Institute of Bioengineering (Nanjing, China).

\section{ROS Detection by Fluorescence Microscopy}

2',7'-dichlorofluorescein diacetate (DCFH-DA) solution (Servicebio, Wuhan, China; Catalog: G1045) was added to frozen sections of the cardiac tissues and cultured in a $37^{\circ} \mathrm{C}$ incubator away from light for $30 \mathrm{~min}$. Then, the sections were placed in phosphate-buffered saline (PBS) and washed by shaking on the decolorizing shaker 3 times, each time for $5 \mathrm{~min}$. DCFH-DA is rapidly turned into fluorescent compound 2.7-dichlorofluorescein (DCF) by ROS. The fluorescence intensity was measured at 488 $\mathrm{nm}$ of excitation wavelength and $525 \mathrm{~nm}$ of emission wavelength after washing with phosphate buffer solution. Sections were observed under a fluorescence microscope, and images were collected. The ROS-positive cells labeled are red, and Image-Pro Plus software was used for quantification.

\section{Measurement of Inflammatory Cytokines}

Heart tissue samples were taken and immediately placed in liquid nitrogen at $-196{ }^{\circ} \mathrm{C}$ for standby application. Briefly, according to manufacturer's instructions, the levels of interleukin-1 $\beta$ (IL-1 $\beta$ ) (Multi Sciences, Hangzhou, China; Catalog: EK301B/3-01), tumor necrosis factor- $\alpha$ (TNF- $\alpha$ ) (Thermo Fisher Scientific, Massachusetts, America; Catalog: 88-7340), and interleukin-6 (IL-6) (Multi Sciences, Hangzhou, China; Catalog: EK306/3-01) in cardiac tissues were detected by enzyme-linked immunosorbent assay (ELISA).

\section{Western Blotting}

The heart samples were homogenized using RIPA lysate. After storing on ice for $20 \mathrm{~min}$, the total proteins were collected by centrifuging the lysis buffer at $12,000 \mathrm{rpm}$ for $10 \mathrm{~min}$ at $4{ }^{\circ} \mathrm{C}$. Sodium dodecyl sulfate-polyacrylamide gel electrophoresis was used to separate the same amounts of protein, and then proteins were transferred to polyvinylidene difluoride membranes that were soaked with blocking buffer including $5 \%$ non-fat milk for $1 \mathrm{~h}$ at $37^{\circ} \mathrm{C}$. The membranes were then incubated overnight with anti-Bcl-2 associated X protein (Bax) (Servicebio, Wuhan, China; Catalog: GB11690, diluted at 1:1000), anti-B-cell lymphoma 2 (Bcl-2) (Cloud-clone, Wuhan, China; Catalog: PAA778Mu01, diluted at 1:1000), anti-Caspase-3 (Proteintech, Wuhan, China; Catalog: 66470-2-lg, diluted at 1:1000), anti-NF-kB (Servicebio, Wuhan, China; Catalog: GM1003, diluted at 1:2000), anti-TLR4 (Servicebio, Wuhan, China; Catalogue: GB11519, diluted at 1:1000), anti-Nrf2 (Servicebio, Wuhan, China; Catalogue: GB13148-1, diluted at 1:1000), or mouse antibody $\beta$-actin (Servicebio, Wuhan, China; Catalogue: GB12001, diluted at 1:1000). Next, the membranes were washed three times with PBS. Then, the membrane was detected in darkness at $37{ }^{\circ} \mathrm{C}$ with secondary antibodies for $2 \mathrm{~h}$. The optical density of the target band was analyzed by Alpha software after the film was scanned.

\section{Statistical Analysis}

The measurement values are shown as the mean \pm standard error of the mean (SEM), and the differences in data among groups were analyzed by one-way analysis of variance (ANOVA) followed by Tukey's test using Origin Pro version 9.1 software. $P$-value $<0.05$ was considered statistically significant.

\section{Results}

\section{Effects of MglG on Body Weight, Food and Water Consumption}

The body weight and food and water consumption data after 7 days of feeding were shown in Table 1. Compared with CONT, these parameters were significantly decreased in ATO

Table I General Observations in Mice

\begin{tabular}{|l|c|c|c|c|c|}
\hline General Observation & Con & ATO & MgIG & H-MgIG & L-MgIG \\
\hline Initial body weight (g) & $21.9 \pm 1.2$ & $22.1 \pm 1.5$ & $22.7 \pm 1.3$ & $22.2 \pm 1.6$ & $22.0 \pm 1.1^{\#}$ \\
Final body weight (g) & $30.7 \pm 0.6$ & $26.8 \pm 0.6^{* *}$ & $30.5 \pm 0.4$ & $29.2 \pm 0.5^{\# \#}$ & $28.2 \pm 0.7^{\#}$ \\
Mean food consumption (g/mouse/day) & $7.8 \pm 0.2$ & $5.4 \pm 0.2^{* *}$ & $7.6 \pm 0.1$ & $6.4 \pm 0.1^{\# \#}$ & $6.0 \pm 0.2^{\#}$ \\
Mean water consumption (mL/mouse/day) & $6.3 \pm 0.2$ & $4.6 \pm 0.3^{* *}$ & $6.2 \pm 0.1$ & $5.8 \pm 0.2^{\# \#}$ & $5.3 \pm 0.1^{\#}$ \\
Mortality (ratio \%) & 0.00 & 0.00 & 0.00 & 0.00 & 0.00 \\
\hline
\end{tabular}

Notes: Values are given as mean \pm SEM or as ratio. Compared with the CONT group $(* * P<0.01)$; compared to the ATO group $\left({ }^{\#} P<0.05,{ }^{\#} P<0.0 \mathrm{I}\right), \mathrm{n}=10$. 
group $(P<0.01$ or $P<0.05)$. Compared to the ATO group, these parameters were obviously raised in the L-MgIG and H-MgIG groups $(P<0.01$ or $P<0.05)$. Furthermore, the MgIG alone group shows no differences compared to CONT $(P>0.05)$. Moreover, no mice died in any group.

\section{Effects of MgIG on Cardiac Histopathology}

Figure 2 shows the heart histopathology changes using an optical microscope. The myocardial tissue structure from the CONT group and MgIG group had regular cell distributions, the cell membrane was intact, and the nucleus was clear. In contrast, the myocardial tissue structure in ATO group was obviously damaged, with inflammatory cells infiltrating the tissues, myofibrillar loss, cytoplasmic vacuolization, and cardiomyocyte necrosis. These pathological changes were ameliorated in the mice that received the $\mathrm{L}-\mathrm{MgIG}$ and $\mathrm{H}-\mathrm{MgIG}$ treatments. Therefore, MgIG treatment significantly reduced the ATO-induced myocardial pathological changes and its effect was shown to be dose-dependent. Furthermore, the MgIG alone group shows no difference compared to CONT $(P>0.05)$.

\section{Effects of MgIG on Serum CK and LDH}

Figure 3 shows the levels of serum $\mathrm{CK}$ and $\mathrm{LDH}$, which were detected to assess myocardial function. The activities of LDH and CK were markedly increased in the ATO group compared with CONT $(P<0.01)$, but the levels of $\mathrm{CK}$ and $\mathrm{LDH}$ in L-MgIG and H-MgIG groups were significantly decreased compared to the ATO group $(P<0.01$ or $P<0.05)$. Furthermore, the MgIG alone group shows no difference compared with CONT $(P>0.05)$. These results indicate that treatment with $\mathrm{L}-\mathrm{MgIG}$ and $\mathrm{H}-\mathrm{MgIG}$ reduced the activity of CK and LDH.

\section{Effects of MgIG on Oxidative Stress}

Figure 4 shows that the serum levels of GSH-Px, SOD, and CAT were obviously decreased in the ATO group $(P<0.01)$ and the content of MDA was elevated $(P<0.01)$ when compared with the CONT group. A marked reduction in MDA level was detected in the L-MgIG and H-MgIG treated groups $(P<0.05$ or $P<0.01)$ compared to the ATO treatment. The activities of SOD, GSH-Px, and CAT were raised in both the L-MgIG and H-MgIG groups $(P<0.01$ or $P<0.05)$. On the other hand, the MgIG alone group shows no difference compared with CONT $(P>0.05)$.
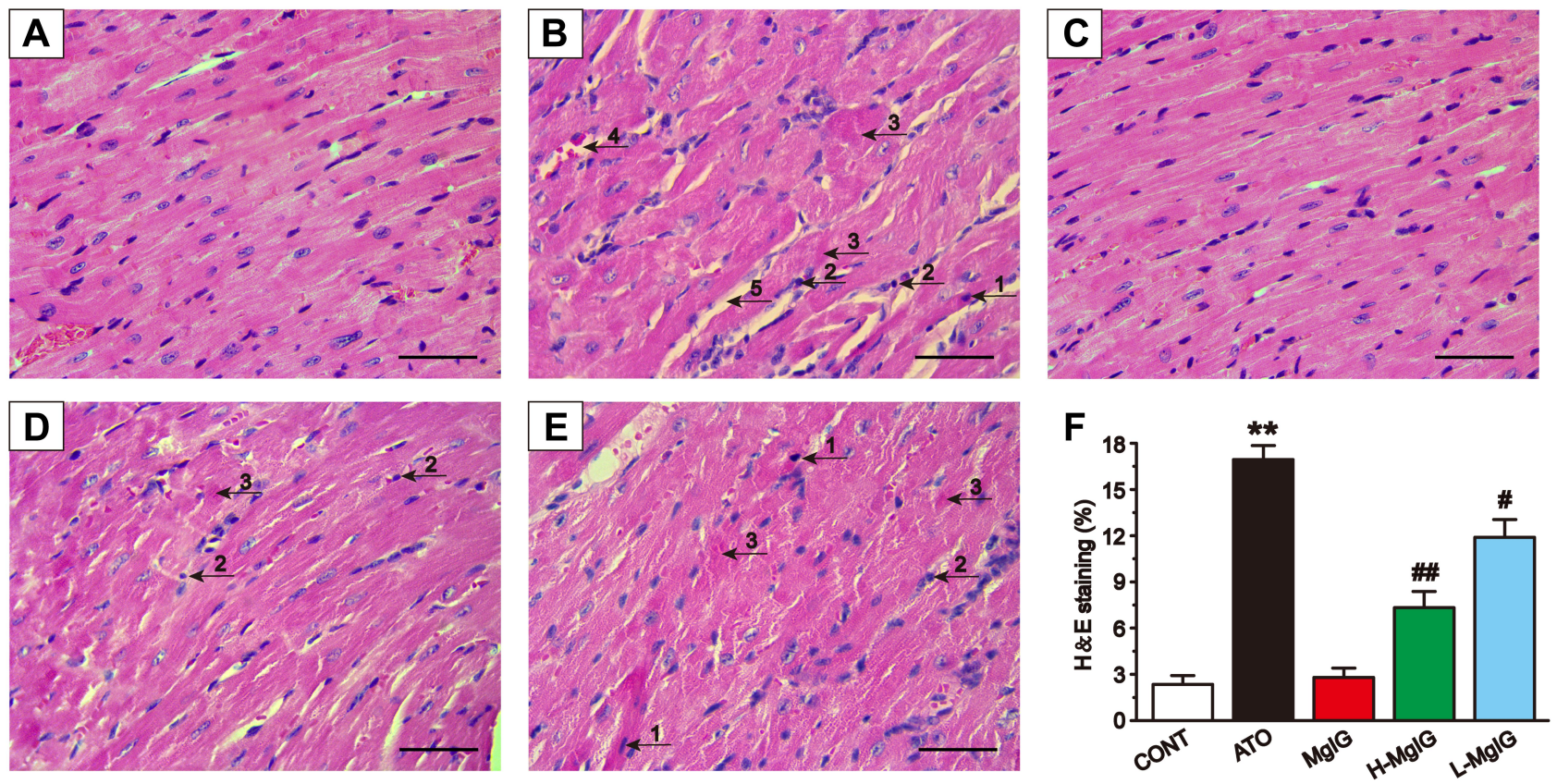

Figure 2 Effects of MgIG on pathological changes of cardiac tissue as surveyed by H\&E staining. Scale bar $=50 \mu \mathrm{m}(\mathrm{H \& E}, 400 \times)$. Myocardial tissues are respectively from the CONT group (A), ATO group (B), MgIG alone treatment group (C), H-MgIG group (D), and L-MgIG group (E). The arrows on the myocardial tissue images represent The area of myocardial injury in each group was calculated (F). The arrows on the images of myocardial tissue represent apoptosis (I), inflammatory cell infiltration (2), myocardial necrosis (3), capillary dilatation and congestion (4), and intermyocardial edema (5), respectively. The values were presented as the mean \pm SEM. $* * P<0.01$ vs CONT; ${ }^{\#} P<0.05,{ }^{\#} P<0.01$ vs the ATO group, $\mathrm{n}=6$. 

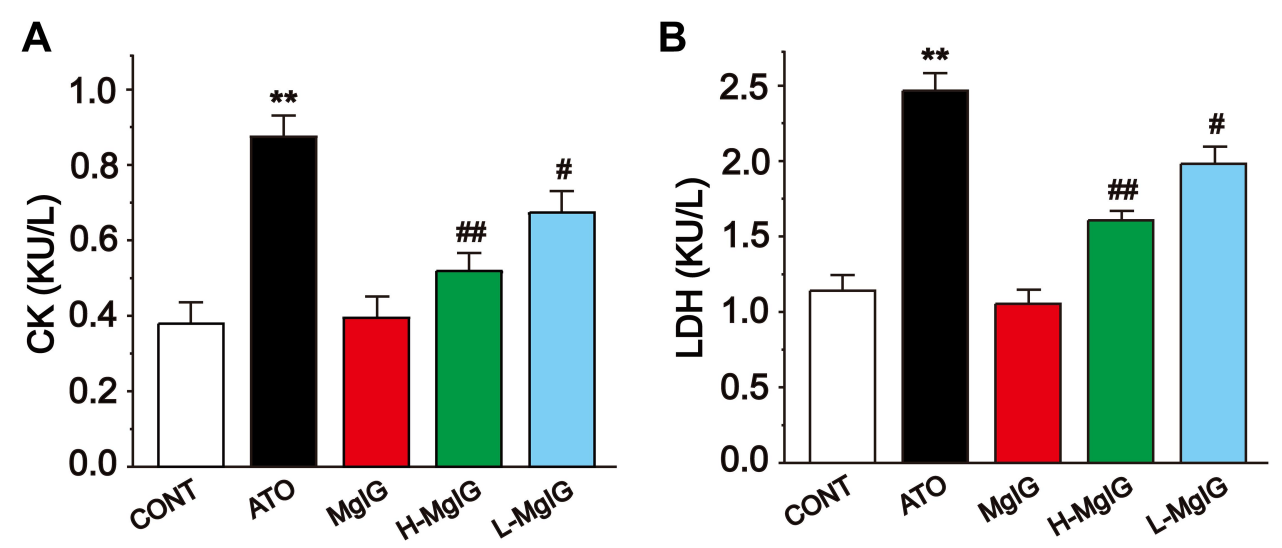

Figure 3 Effects of MgIG on the activities of CK (A) and LDH (B). The values were presented as the mean \pm SEM. $* * P<0.01$ vs CONT; ${ }^{\#} P<0.05$, ${ }^{\# \#} P<0.01$ vs the ATO group, $\mathrm{n}=10$.

A

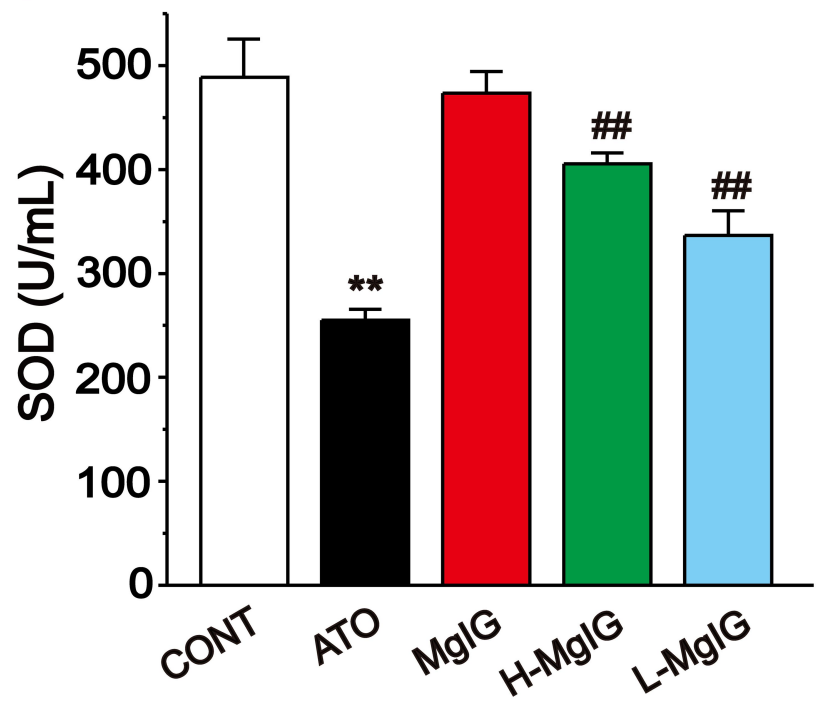

C

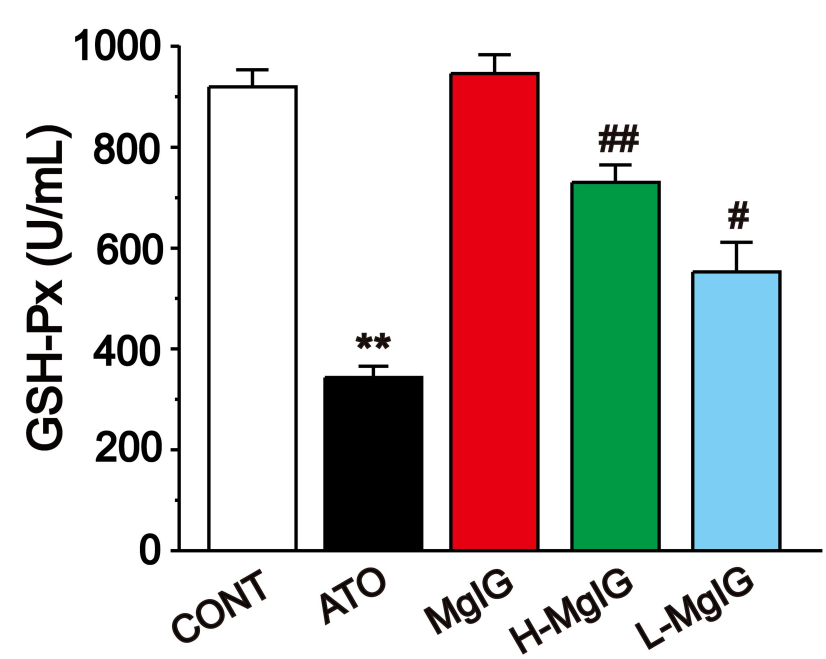

B

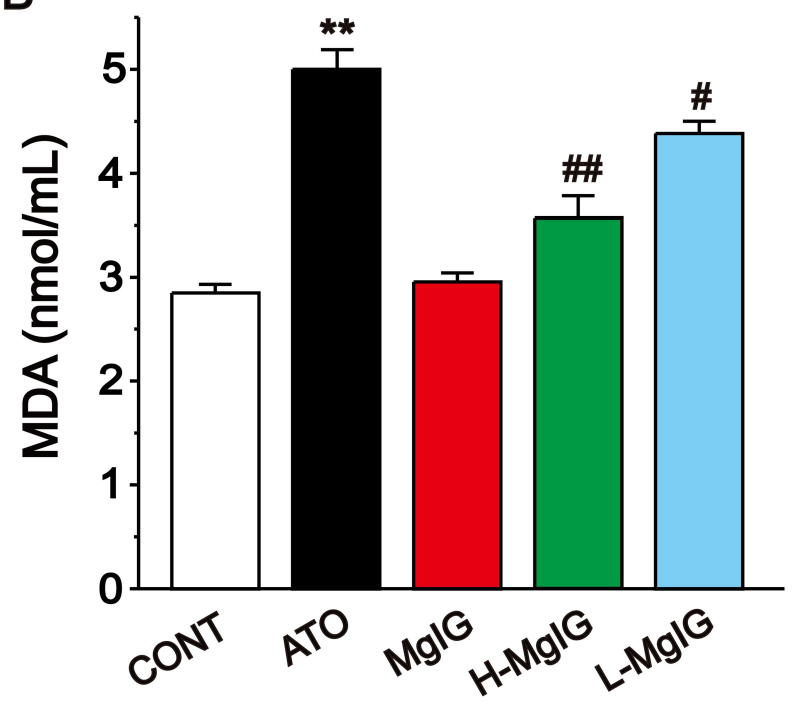

D

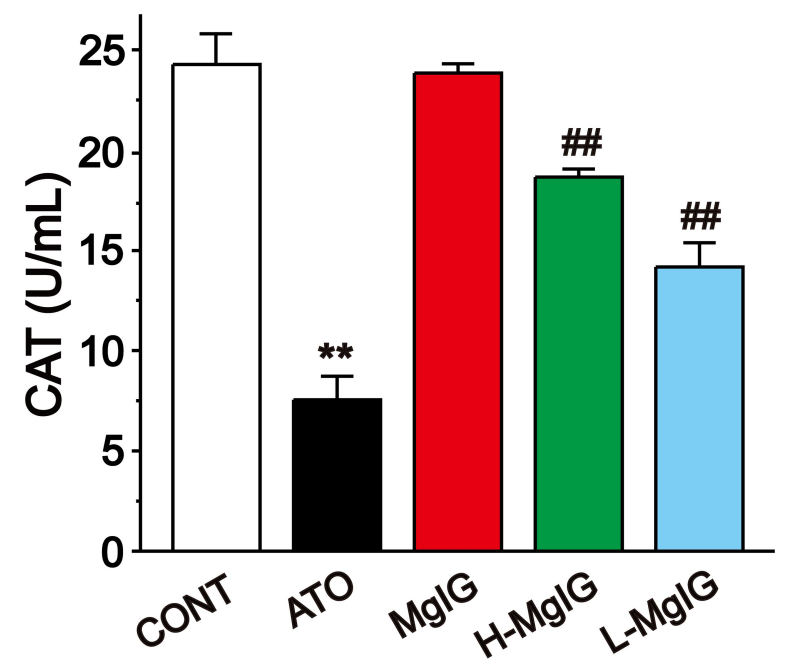

Figure 4 Effects of MgIG on the levels of SOD (A), MDA (B), GSH-Px (C) and CAT (D). The values were presented as the mean \pm SEM. ** $P<0.0$ I vs CONT; ${ }^{\#} p<0.05, \# P<0.01$ vs the ATO group, $n=10$. 


\section{Effects of MgIG on ROS Production}

Figure 5 shows the fluorescent probe analysis findings used to assess the generation of ROS. The intracellular ROS level of ATO group was higher than that of CONT group $(P<0.01)$, while that of $\mathrm{L}-\mathrm{MgIG}$ and H-MgIG groups were significantly lower than that of ATO group $(P<0.01)$. Furthermore, the MgIG alone group shows no difference compared to CONT $(P>$ $0.05)$. These data indicate that the protection of L-MgIG and H-MgIG on heart damage could be relevant to the reduction of ROS production and oxidative stress.

\section{Effects of MgIG on IL-I $\beta$, IL-6, and TNF- $\alpha$ Levels}

The levels of IL-1 $\beta$, IL- 6 , and TNF- $\alpha$ in cardiac tissues were detected by ELISA (Figure 6). The levels of IL-6, IL$1 \beta$, and TNF- $\alpha$ were obviously elevated in the ATO group compared to the CONT group $(P<0.01)$, while these parameters in the L-MgIG and H-MgIG groups were significantly lower than ATO group $(P<0.01)$. Furthermore, the MgIG alone group shows no difference compared with CONT $(P>0.05)$. Therefore, treatment with L-MgIG and $\mathrm{H}-\mathrm{MgIG}$ could markedly reduce the activity of inflammatory cytokines.

\section{Effects of MglG on Bax, Bcl-2, and Caspase-3 Protein Expressions}

To evaluate the expression of apoptosis factors, we tested the levels of Bcl-2, Caspase-3, and Bax in heart tissues (Figure 7). Compared to the CONT group, the expressions of Caspase-3 and Bax were markedly upregulated in the ATO group $(P<0.01)$. Furthermore, Bcl-2 expression was markedly reduced in the ATO group $(P<0.01)$. After MgIG treated, Caspase- 3 and Bax were markedly downregulated $(P<0.05$ or $P<0.01)$, while Bcl-2 expression was increased in the L-MgIG and H-MgIG groups $(P<$ 0.01) compared with the ATO group. Furthermore, the MgIG alone group shows no difference compared with CONT $(P>0.05)$.

\section{Effects of MglG on Nrf2, TLR4, and NF- $\kappa B$ Protein Expressions}

Western blotting analysis was used to analyze the expressions of Nrf2, TLR4, and NF-kB (Figure 8). In the ATO group, the level of Nrf2 was observably lower than that in CONT $(P<0.01)$, and the expressions of TLR4 and NF$\kappa \mathrm{B}$ were upregulated in ATO group $(P<0.01)$. Conversely, L-MgIG and $\mathrm{H}-\mathrm{MgIG}$ treatments obviously enhanced the Nrf2 expression and reduced the TLR4 and NF- $\kappa \mathrm{B}$ expressions compared with the ATO group
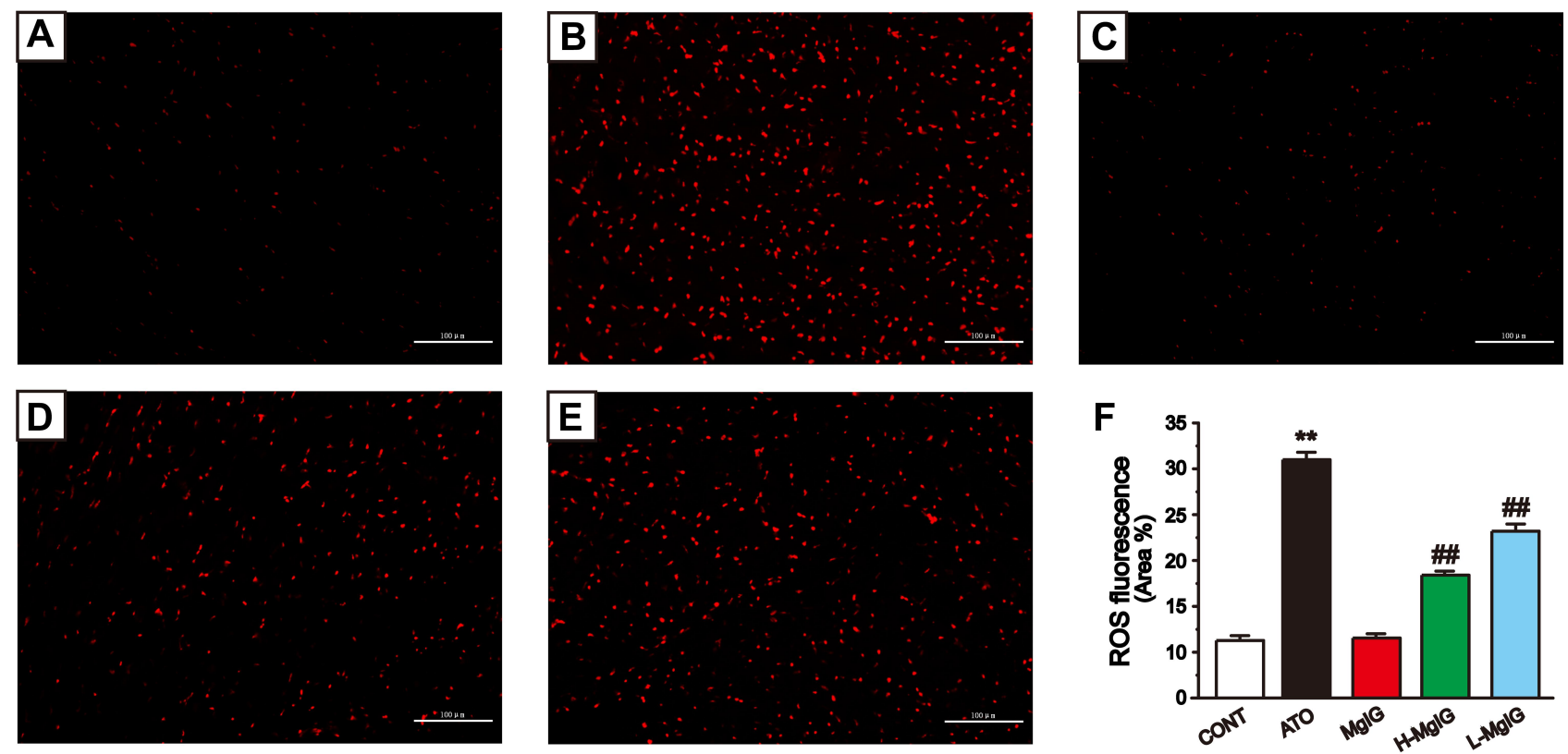

Figure 5 Effects of MgIG on the levels of ROS. Fluorescence images of different groups (A), CONT group; (B), ATO group; (C), MgIG alone treated group; (D), H-MgIG group; (E), L-MgIG group) and the ratio graph (F) about ROS are presented. Scale bar $=100 \mu \mathrm{m}(200 \times)$. The values were presented as the mean \pm SEM. $* * P<0.0 \mathrm{I}$ vs CONT; ${ }^{\#} p<0.01$ vs the ATO group, $n=6$. 
A

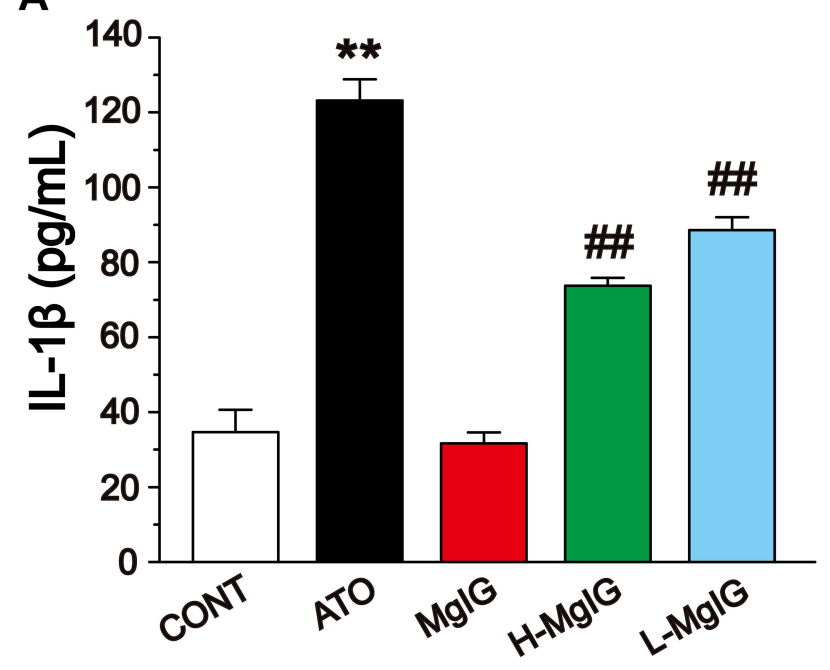

C

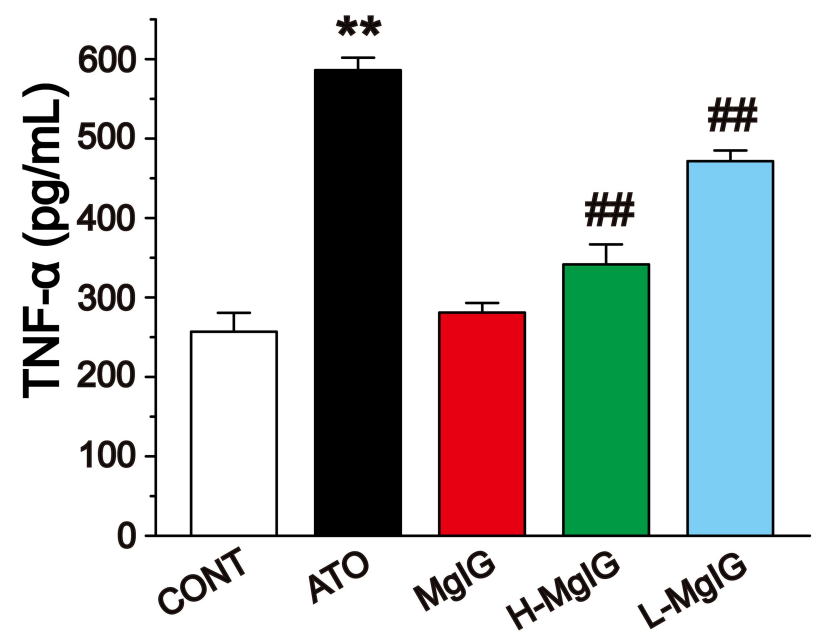

B

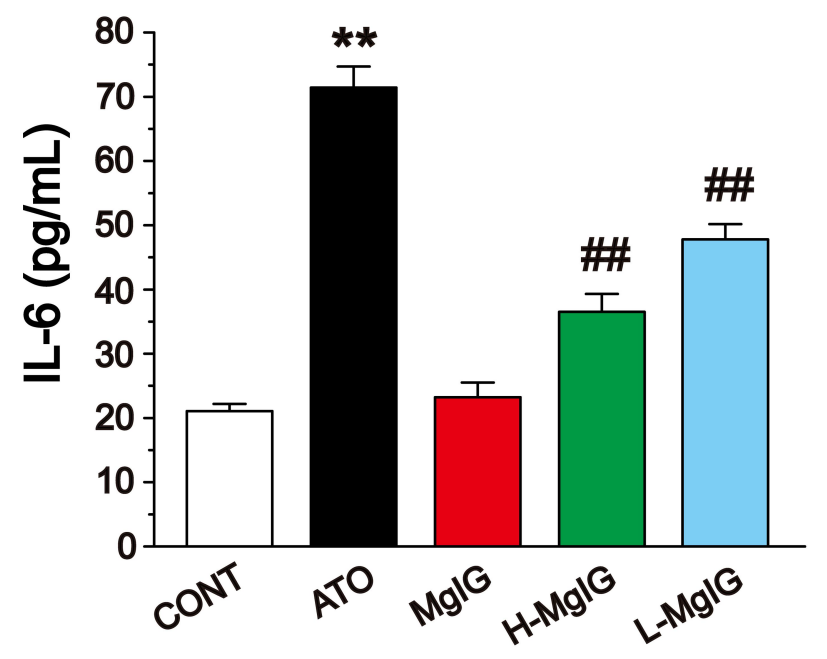

Figure 6 Effects of MgIG on the expressions of IL-I $\beta(\mathbf{A})$, IL-6 (B) and TNF- $\alpha(\mathbf{C})$. The values were presented as the mean \pm SEM. ${ }^{* *} P<0.0 \mathrm{I}$ vs CONT; ${ }^{\# \#} P<0.0 \mathrm{I}$ vs the ATO group, $\mathrm{n}=10$.

$(P<0.05$ or $P<0.01)$. Furthermore, the MgIG alone group shows no difference compared with CONT group $(P>0.05)$.

\section{Discussion}

ATO has been found to be a significantly effective drug for various diseases, especially in APL, but its cardiotoxicity restricts its therapeutic index. ${ }^{33,34}$ During cardiotoxicity, myocarditis, pericarditis and myocardial infarction can occur, that may ultimately lead to heart failure. ${ }^{33,35}$ Thus, the heart muscle cannot pump with sufficient force to supply the body with blood containing essential $\mathrm{O}_{2}$ and nutrients. ${ }^{3}$ Therefore, it is important to identify novel preventive drugs to reduce the severe cardiotoxicity of ATO. Our previous findings have suggested the possibility that
MgIG has a protective effect on cardiomyocytes. ${ }^{30}$ Accordingly, here, we further investigate the effects of MgIG on the Nrf2 and TLR4/NF- $\kappa B$ signal pathway and its underlying mechanisms against the ATO-induced cardiotoxicity (Figure 9). The selection of doses of ATO and MgIG is based on our preliminary experiments and previous studies. ${ }^{26,30,36-38}$

Oxidative stress, inflammation, and apoptosis are crucial causes of ATO-induced heart injury. ${ }^{30}$ ATO diffuses into the cytoplasm through the cell membrane and produces oxidative stress, which produces a large amount of ROS and causes oxidative damage to mitochondrial and then releases pro-apoptotic proteins into the cytosol, thereby producing cytotoxic effects leading to apoptosis and organ damage. ${ }^{39-41}$ Excessive ROS also plays an 
A

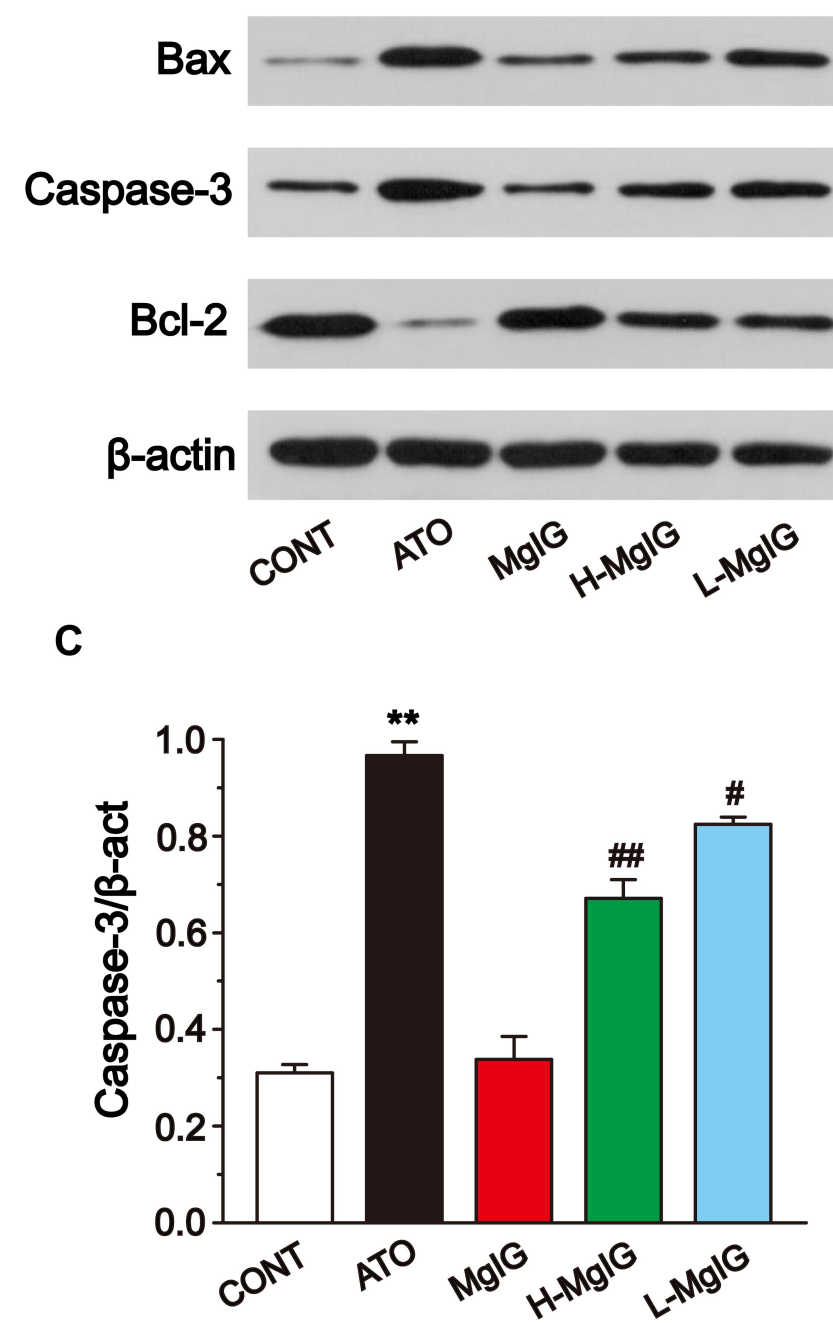

B

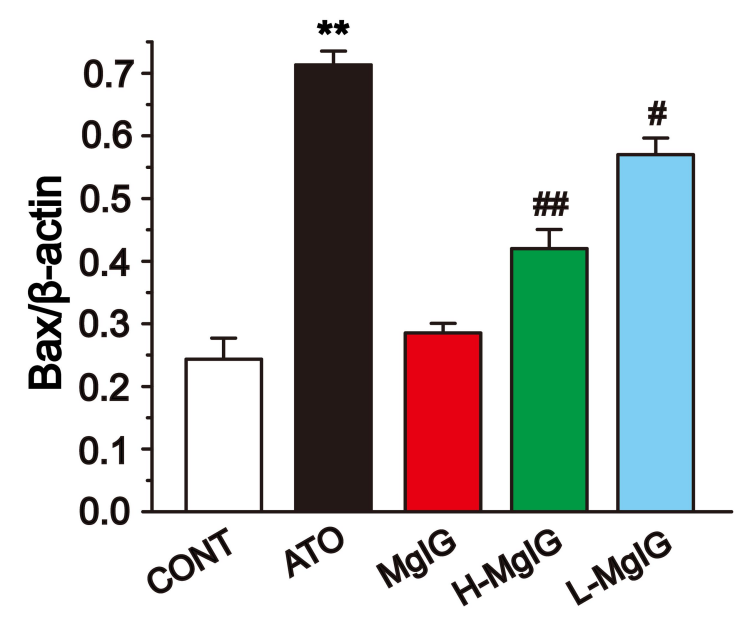

D

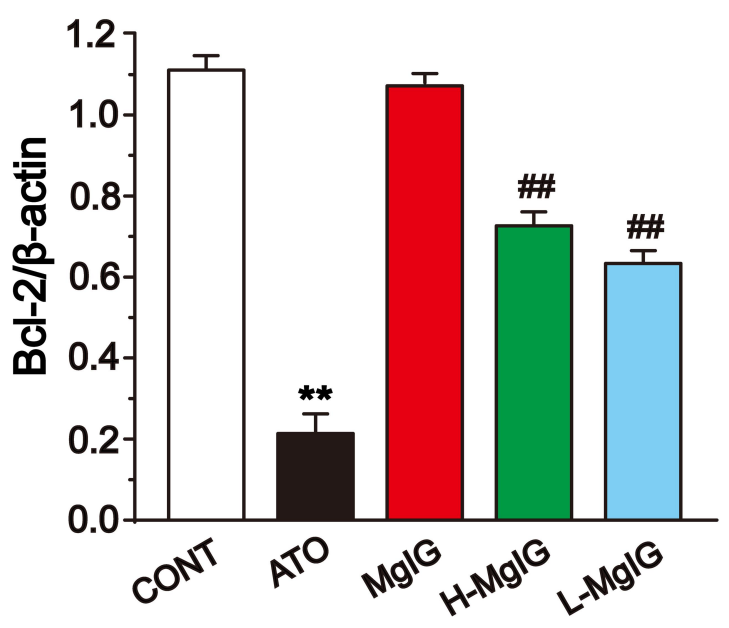

Figure 7 Effects of MgIG on the expression of Bax, Caspase-3, and Bcl-2 (A). The band intensities of Bax (B), caspase-3 (C), and Bcl-2 (D) were analyzed by normalization to $\beta$-actin. The values were presented as the mean \pm SEM. $* * P<0.01$ vs CONT; ${ }^{\#} P<0.05,{ }^{\#} P<0.01$ vs the ATO group, $n=3$.

important role in many cellular processes and causes altered cellular signal transduction, such as activation of transcription factors and changes in gene expression, leading to damage in DNA, lipids, and proteins, aggravated oxidative stress-induced damage, and the release of the pro-inflammatory cytokines. ${ }^{42,43}$ The increased oxidative stress and subsequent inflammatory responses lead to increased apoptosis. ${ }^{44}$

We found that the mice in the ATO group had significantly reduced weight, food, and water consumption. However, these parameters in the L-MgIG and H-MgIG groups were obviously higher than in the ATO group, suggesting that $\mathrm{MgIG}$ could alleviate the adverse reactions of patients with abnormal digestion, absorption, and metabolism caused by chemotherapeutic drugs (Table 1). H\&E stained pathological sections can directly observe the pathological changes of the myocardium, which is one of the important indexes to judge myocardial damage. ${ }^{45}$ The myocardial tissue structure in ATO group was discovered to have inflammatory cell infiltration, serious muscle fibre damage, and myocardial necrosis, while the MgIG treatment groups markedly improved this condition, confirming that MgIG has obvious protection on myocardial changes caused by ATO (Figure 2). ${ }^{46}$ Also, CK and LDH enzymes were released in large quantities after myocardial injury or necrosis, but the activities of LDH and CK were obviously reduced in $\mathrm{L}-\mathrm{MgIG}$ and $\mathrm{H}-\mathrm{MgIG}$ treatment groups, which suggests that MgIG can protect the heart by reducing the release of these myocardial markers (Figure 3). 
A
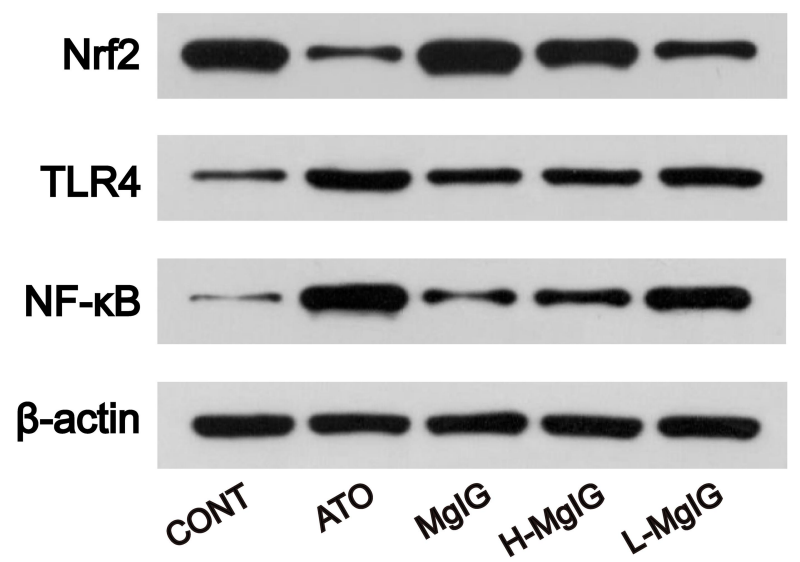

C

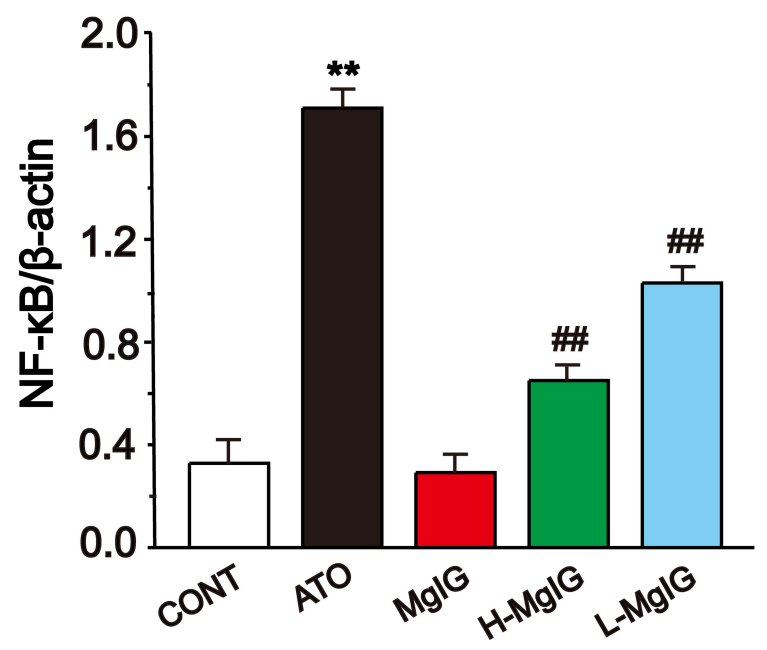

B

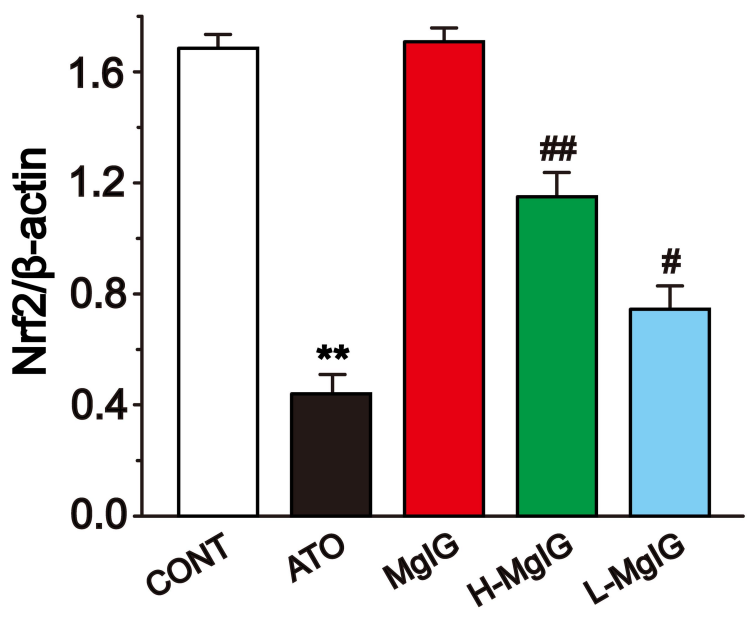

D

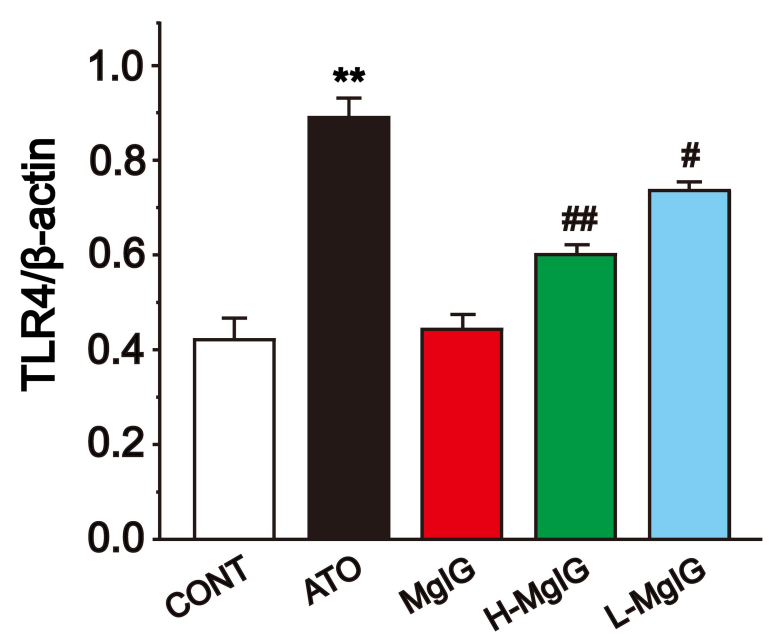

Figure 8 Effects of MgIG on the expressions of Nrf2, TLR4, and NF-kB (A). The band intensities of Nrf2 (B), NF- $\mathrm{B}$ (C), and TLR4 (D) were analyzed by normalization to $\beta$-actin. The values were presented as the mean \pm SEM. ${ }^{* *} P<0.01$ vs CONT; ${ }^{*} P<0.05,{ }^{\#} P<0.01$ vs the ATO group, $n=3$.

ATO causes oxidative stress injury in the body, which could disrupt the balance between oxidants and antioxidants in the process of metabolism. ${ }^{47,48}$ However, MgIG can protect the heart by activating the activity of anti-oxidant enzymes. ${ }^{49}$ SOD, CAT, and GSH-Px, as the three main enzymes in the anti-oxidant system, inhibit the further development of oxidative stress in vivo. ${ }^{49,50}$ The level of MDA could reflect the degree of lipid peroxidation, thereby indirectly reflecting the degree of cell injury. SOD could convert superoxide anion produced by lipid peroxidation into $\mathrm{H}_{2} \mathrm{O}_{2}$, and CAT and GSH-Px transform $\mathrm{H}_{2} \mathrm{O}_{2}$ into oxygen and water, so the activity of these three enzymes are tested at the same time to explore the damage degree of the anti-oxidant system. ${ }^{51-53} \mathrm{MgIG}$ treatment significantly enhanced the levels of GSH-Px, CAT, and
SOD induced by ATO, and decreased the MDA content (Figure 4). Under normal circumstances, the generation and elimination of ROS are balanced, while maintaining a steady state of redox. ${ }^{54}$ Whereas this balance was destroyed after exposure to arsenic, and the production of ROS increased significantly (Figure 5), which is consistent with the literature. ${ }^{55-57}$

The overproduction of ROS can cause cardiomyocyte injury and apoptosis, while MgIG can help to regulate the anti-oxidant system, which will reduce oxidative stress injury induced by ATO (Figure 5). At the same time, oxidative stress plays a role in mediating apoptosis. ${ }^{58}$ ATO caused up-regulation of Caspase-3 and Bax expressions, while the down-regulation of Bcl-2 level (Figure 7). In contrast, Bax and Caspase- 3 proteins were markedly 


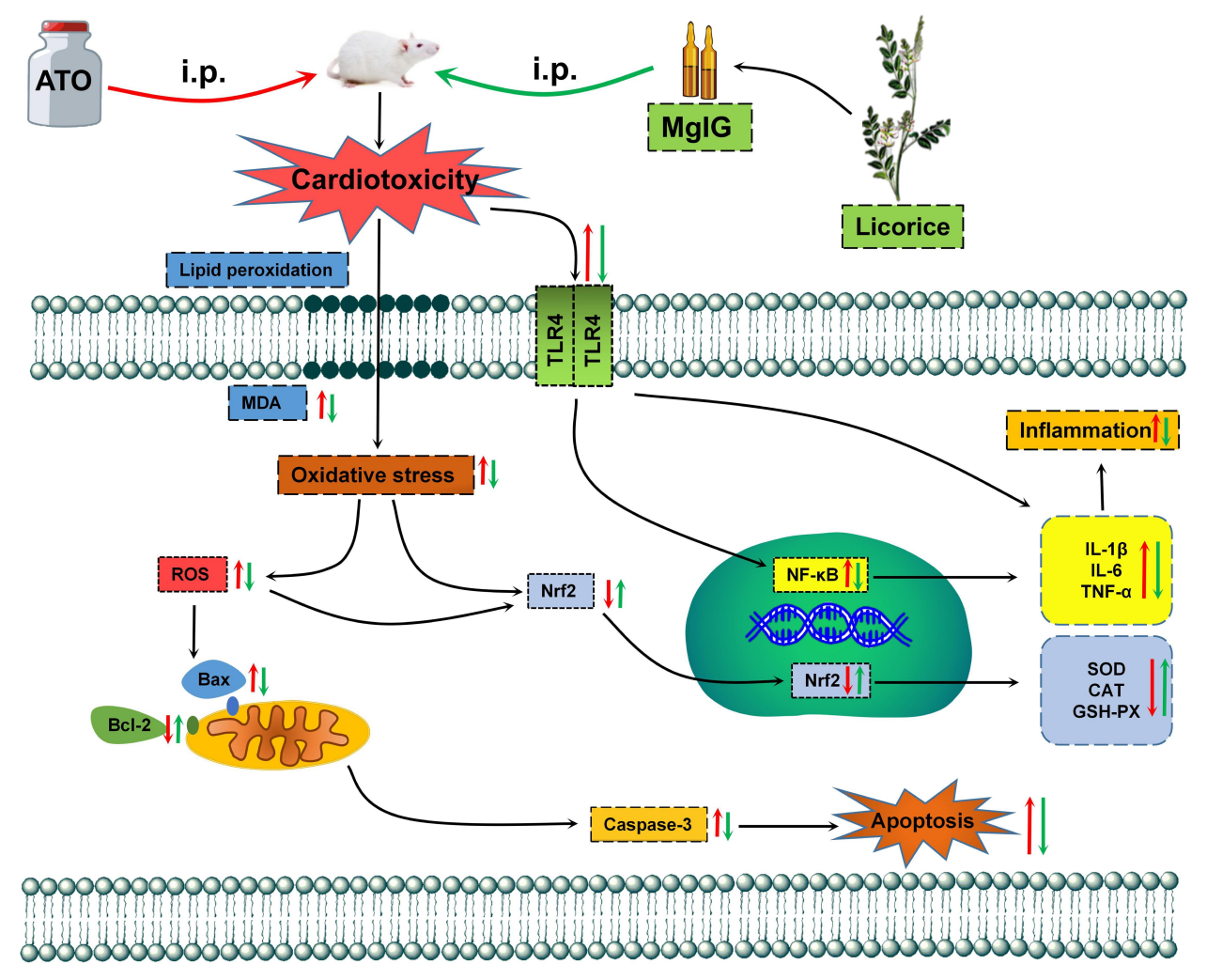

Figure 9 The mechanism for protection of MgIG against ATO-treated cardiotoxicity.

enhanced, and Bcl-2 protein expression was obviously decreased after MgIG treatment (Figure 7). It is widely known that the regulation of the Bcl-2 protein family is mainly mediated by mitochondria. ${ }^{59}$ Oxidative stress could make the Bax translocation to the outer membrane of mitochondria, which will affect the permeability of the outer mitochondrial membrane and finally induces the division of Caspase-3. ${ }^{60} \mathrm{Bc} 1-2$ can stabilize the mitochondrial membrane potential, keep the mitochondria intact, and inhibit Caspase- 3 division. ${ }^{61}$

In the mechanism of anti-oxidative stress, numerous drugs from natural sources display their anti-oxidant effect by activating the Nrf2 pathway. ${ }^{61,62} \mathrm{Nrf} 2$ is the core regulator of Phase II detoxification or anti-oxidant enzymes, which can help protect cardiomyocytes from oxidative damage. ${ }^{63,64} \mathrm{Up}$ regulation of $\mathrm{Nrf} 2$ protein is an adaptive mechanism that could protect cells from oxidative stress. ${ }^{65}$ Here, we report that the Nrf2 protein in the L-MgIG and H-MgIG groups was obviously enhanced, confirming that MgIG activates the Nrf2 signal pathway to protect cardiomyocytes (Figure 8). Within the toll-like receptors family, TLR4 plays an important role and is highly expressed in the heart. TLR4 activates downstream nuclear factors $(\mathrm{NF}-\kappa \mathrm{B})$ by binding to ligands and induces the production of inflammatory cytokines. ${ }^{18,66}$ As one of the important pathways associated with inflammatory response, the activation of the TLR4/NF- $\kappa \mathrm{B}$ signal pathway can lead to the expression of IL- $1 \beta$, IL-6, TNF- $\alpha$, and other inflammatory factors (Figure 6), forming a series of inflammatory responses. ${ }^{67}$ Arsenic poisoning results in an obvious increase in the levels of IL-1 $\beta$, TNF- $\alpha$, IL-6, TLR4, and NF$\kappa \mathrm{B}$ protein, but these trends are reversed by $\mathrm{MgIG}$ treatment (Figure 6 and Figure 8). This indicates that MgIG suppresses the TLR4/NF- $\kappa B$ signalling pathway and decreases the release of IL-1 $\beta$, IL- 6 , and TNF- $\alpha$ inflammatory cytokines.

\section{Conclusion}

MgIG has a significant protective effect on ATOinduced cardiotoxicity. We demonstrate that the cardioprotective effects of MgIG are generated through antioxidation, anti-inflammation, and anti-apoptosis mechanisms, which are associated with the activation of the Nrf2 pathway and inhibition of the TLR4/NF$\kappa \mathrm{B}$ pathway (Figure 9). Based on these findings, the combination of MgIG with ATO is likely to be a promising agent in future clinical practice. However, the combination of MgIG and ATO needs further research in clinical practice. 


\section{Acknowledgments}

The experiment was supported by the Research Foundation of Administration of Traditional Chinese Medicine of Hebei Province, China (No.2019075).

\section{Disclosure}

The authors declare that they have no relevant conflicts of interest for this work.

\section{References}

1. Waalkes MP, Liu J, Ward JM, et al. Mechanisms underlying arsenic carcinogenesis: hypersensitivity of mice exposed to inorganic arsenic during gestation. Toxicology. 2004;198(1-3):31-38. doi:10.1016/j. tox.2004.01.017

2. Chen SC, Chen CC, Kuo CY, et al. Elevated risk of hypertension induced by arsenic exposure in Taiwanese rural residents: possible effects of manganese superoxide dismutase (MnSOD) and 8-oxoguanine DNA glycosylase (OGG1) genes. Arch Toxicol. 2012;86(6):869-878. doi:10.1007/s00204-011-0797-8

3. Ratnaike RN. Acute and chronic arsenic toxicity. Postgrad Med J. 2003;79(933):391-396. doi:10.1136/pmj.79.933.391

4. Lazo G, Kantarjian H, Estey E, et al. Use of arsenic trioxide $\left(\mathrm{As}_{2} \mathrm{O}_{3}\right)$ in the treatment of patients with acute promyelocytic leukemia: the M. D. Anderson experience. Cancer. 2003;97(9):2218-2224. doi:10.1002/cncr.11314

5. Au WY, Kwong YL. Arsenic trioxide: safety issues and their management. Acta Pharmacol Sin. 2008;29(3):296-304. doi: $10.1111 / \mathrm{j} .1745-7254.2008 .00771 . \mathrm{x}$

6. Soignet SL, Frankel SR, Douer D, et al. United States multicenter study of arsenic trioxide in relapsed acute promyelocytic leukemia. J Clin Oncol. 2001;19(18):3852-3860. doi:10.1200/JCO.2001.19.18.3852

7. Shi H, Hudson LG, Ding W, et al. Arsenite causes DNA damage in keratinocytes via generation of hydroxyl radicals. Chem Res Toxicol. 2004;17(7):871-878. doi:10.1021/tx049939e

8. Zhao X, Feng T, Chen H, et al. Arsenic trioxide-induced apoptosis in H9c2 cardiomyocytes: implications in cardiotoxicity. Basic Clin Pharmacol Toxicol. 2008;102(5):419-425. doi:10.1111/j.17427843.2007.00150.x

9. Li Z, Piao F, Liu S, et al. Subchronic exposure to arsenic trioxide-induced oxidative DNA damage in kidney tissue of mice. Exp Toxicol Pathol. 2010;62(5):543-547. doi:10.1016/j. etp.2009.07.003

10. Hughes MF, Beck BD, Chen Y, et al. Arsenic exposure and toxicology: a historical perspective. Toxicol Sci. 2011;123(2):305-332. doi:10.1093/toxsci/kfr184

11. Piao F, Ma N, Hiraku Y, et al. Oxidative DNA damage in relation to neurotoxicity in the brain of mice exposed to arsenic at environmentally relevant levels. J Occup Health. 2005;47(5):445-449. doi:10.1539/joh.47.445

12. Shi H, Shi X, Liu KJ. Oxidative mechanism of arsenic toxicity and carcinogenesis. Mol Cell Biochem. 2004;255(1-2):67-78. doi:10.1023/B:MCBI.0000007262.26044.e8

13. Kessel M, Liu SX, Xu A, et al. Arsenic induces oxidative DNA damage in mammalian cells. Mol Cell Biochem. 2002;234-235(1-2):301-308. doi:10.1023/A:1015927406142

14. Kaspar JW, Niture SK, Jaiswal AK. Nrf2:INrf2(Keap1) signaling in oxidative stress. Free Radic Biol Med. 2009;47(9):1304-1309. doi:10.1016/j.freeradbiomed.2009.07.035

15. Wang M, Sun G, Wu P, et al. Salvianolic Acid B prevents arsenic trioxide-induced cardiotoxicity in vivo and enhances its anticancer activity in vitro. Evid Based Complement Alternat Med. 2013;2013:759483. doi:10.1155/2013/759483
16. Cachofeiro V, Goicochea M, de Vinuesa SG, et al. Oxidative stress and inflammation, a link between chronic kidney disease and cardiovascular disease. Kidney Int Suppl. 2009;111(Suppl):S4-S9. doi:10.1038/ki.2008.516

17. Cai SY, Chen JX, Li YS. Dioscin protects against diabetic nephropathy by inhibiting renal inflammation through TLR4/NF- $\kappa B$ pathway in mice. Immunobiology. 2020;225(3):151941. doi:10.1016/j. imbio.2020.151941

18. Frantz S, Ertl G, Bauersachs J. Mechanisms of disease: toll-like receptors in cardiovascular disease. Nat Clin Pract Cardiovasc Med. 2007;4(8):444-454. doi:10.1038/ncpcardio0938

19. James TN. Long reflections on the QT interval: the sixth annual Gordon K. Moe Lecture. J Cardiovasc Electrophysiol. 1996;7 (8):738-759. doi:10.1111/j.1540-8167.1996.tb00581.x

20. Best PJ, Hasdai D, Sangiorgi G, et al. Apoptosis. Basic concepts and implications in coronary artery disease. Arterioscler Thromb Vasc Biol. 1999;19(1):14-22. doi:10.1007/s100169900229

21. Zhao XY, Li GY, Liu Y, et al. Resveratrol protects against arsenic trioxide-induced cardiotoxicity in vitro and in vivo. Br J Pharmacol. 2008;154(1):105-113. doi:10.1038/bjp.2008.81

22. Wang X, Zhang H, Chen L, et al. Liquorice, a unique "guide drug" of traditional Chinese medicine: a review of its role in drug interactions. J Ethnopharmacol. 2013;150(3):781-790. doi:10.1016/j.jep.2013.09.055

23. Ren J, Wang ZG. Pharmacological research on the effect of licorice. J Tradit Chin Med. 1988;8(4):307-309.

24. Wang ZJ, Ren J, Zhang R. Immunoregulatory studies on ammonium glycyrrhizinate in mice. Chin J Pharmacol Toxicol. 1990;4:36-38.

25. Ojha S, Golechha M, Kumari S, et al. Glycyrrhiza glabra protects from myocardial ischemia-reperfusion injury by improving hemodynamic, biochemical, histopathological and ventricular function. Exp Toxicol Pathol. 2013;65(1-2):219-227. doi:10.1016/j.etp.2011.08.011

26. Jiang W, Chen Q, Li P, et al. Magnesium isoglycyrrhizinate attenuates lipopolysaccharide-induced depressive-like behavior in mice. Biomed Pharmacother. 2017;86:177-184. doi:10.1016/j. biopha.2016.12.033

27. Beskina OA, Abramov A, Gabdulkhakova AG, et al. Possible mechanisms of antioxidant activity of glycyrrhizic acid. Biomed Khim. 2006;52(1):60-68.

28. Chen KJ, Chen WY, Chen X, et al. Increased elimination of paclitaxel by magnesium isoglycyrrhizinate in epithelial ovarian cancer patients treated with paclitaxel plus cisplatin: a pilot clinical study. Eur J Drug Metab Pharmacokinet. 2014;39(1):25-31. doi:10.1007/ s13318-013-0136-y

29. Lin Y, Zhu J, Zhang X, et al. Inhibition of cardiomyocytes hypertrophy by resveratrol is associated with amelioration of endoplasmic reticulum stress. Cell Physiol Biochem. 2016;39(2):780-789. doi: $10.1159 / 000447788$

30. Ma D, Zhang J, Zhang Y, et al. Inhibition of myocardial hypertrophy by magnesium isoglycyrrhizinate through the TLR4/NF-kappaB signaling pathway in mice. Int Immunopharmacol. 2018;55:237-244. doi:10.1016/j.intimp.2017.12.019

31. Zhao Z, Liu M, Zhang Y, et al. Cardioprotective effect of monoammonium glycyrrhizinate injection against myocardial ischemic injury in vivo and in vitro: involvement of inhibiting oxidative stress and regulating $\mathrm{Ca}^{2+}$ homeostasis by L-type calcium channels. Drug Des Devel Ther. 2020;14:331-346. doi:10.2147/DDDT.S232130

32. Lin Y, Zhang Y, Song Q, et al. Magnesium isoglycyrrhizinate inhibits L-type $\mathrm{Ca}^{2+}$ channels, $\mathrm{Ca}^{2+}$ transients, and contractility but not hERG $\mathrm{K}^{+}$channels. Arch Pharm Res. 2017;40(10):1135-1145. doi:10.1007/ s12272-017-0938-6

33. Vineetha VP, Raghu KG. An Overview on arsenic trioxide-induced cardiotoxicity. Cardiovasc Toxicol. 2019;19(2):105-119. doi:10.1007/s12012-018-09504-7

34. Mathews VV, Paul MV, Abhilash M, et al. Myocardial toxicity of acute promyelocytic leukaemia drug-arsenic trioxide. Eur Rev Med Pharmacol Sci. 2013;17(Supp11):34-38. doi:10.1038/npp.2012.191 
35. Albini A, Pennesi G, Donatelli F, et al. Cardiotoxicity of anticancer drugs: the need for cardio-oncology and cardio-oncological prevention. J Natl Cancer Inst. 2010;102(1):14-25. doi:10.1093/ jnci/djp440

36. Jin W, Xue Y, Xue Y, et al. Tannic acid ameliorates arsenic trioxide-induced nephrotoxicity, contribution of NF-kappaB and Nrf2 pathways. Biomed Pharmacother. 2020;126:110047. doi:10.1016/j.biopha.2020.110047

37. Hemmati AA, Olapour S, Varzi $\mathrm{HN}$, et al. Ellagic acid protects against arsenic trioxide-induced cardiotoxicity in rat. Hum Exp Toxicol. 2018;37(4):412-419. doi:10.1177/0960327117701986

38. Birari LA, Mahajan UB, Patil KR, et al. Aloin protects against arsenic trioxide-induced myocardial membrane damage and release of inflammatory cytokines. Naunyn Schmiedebergs Arch Pharmacol. 2020;393(8):1365-1372. doi:10.1007/s00210-020-01833-1

39. Schieber M, Chandel NS. ROS function in redox signaling and oxidative stress. Curr Biol. 2014;24(10):R453-462. doi:10.1016/j. cub.2014.03.034

40. Zhao H, He Y, Li S, et al. Subchronic arsenism-induced oxidative stress and inflammation contribute to apoptosis through mitochondrial and death receptor dependent pathways in chicken immune organs. Oncotarget. 2017;8(25):40327-40344. doi:10.18632/ oncotarget. 16960

41. Kumar S, Yedjou CG, Tchounwou PB. Arsenic trioxide induces oxidative stress, DNA damage, and mitochondrial pathway of apoptosis in human leukemia (HL-60) cells. J Exp Clin Cancer Res. 2014;33:42. doi:10.1186/1756-9966-33-42

42. Kirkinezos IG, Moraes CT. Reactive oxygen species and mitochondrial diseases. Semin Cell Dev Biol. 2001;12(6):449-457. doi: $10.1006 / \mathrm{scdb} .2001 .0282$

43. Baj G, Arnulfo A, Deaglio S, et al. Arsenic trioxide and breast cancer: analysis of the apoptotic, differentiative and immunomodulatory effects. Breast Cancer Res Treat. 2002;73(1):61-73. doi:10.1023/A:1015272401822

44. Zhang C, Wang F, Zhang Y, et al. Celecoxib prevents pressure overload-induced cardiac hypertrophy and dysfunction by inhibiting inflammation, apoptosis and oxidative stress. J Cell Mol Med. 2016;20(1):116-127. doi:10.1111/jcmm.12709

45. Fu ZJ, Li CM, Wang TH, et al. Vascular endothelial growth factor expression and pathological changes in the local tissue of facial hemangiomas following injections with pure alcohol. Oncol Lett. 2015;9(3):1099-1103.

46. Yu X, Wang Z, Shu Z, et al. Effect and mechanism of sorbus pohuashanensis (Hante) hedl flavonoids protect against arsenic trioxide-induced cardiotoxicity. Biomed Pharmacother. 2017;88:1-10. doi:10.1016/j.biopha.2016.12.130

47. Jomova K, Jenisova Z, Feszterova M, et al. Arsenic: toxicity, oxidative stress and human disease. J Appl Toxicol. 2011;31(2):95-107. doi:10.1002/jat.1649

48. Flora SJ. Arsenic-induced oxidative stress and its reversibility. Free Radic Biol Med. 2011;51(2):257-281. doi:10.1016/j.freeradbio med.2011.04.008

49. Wu Z, Zhang Y, Song T, et al. Magnesium isoglycyrrhizinate ameliorates doxorubicin-induced acute cardiac and hepatic toxicity via anti-oxidant and anti-apoptotic mechanisms in mice. Exp Ther Med. 2018;15(1):1005-1012. doi:10.3892/etm.2017.5470

50. Wang Y, Zhang Z, Wang X, et al. Amelioration of ethanol-induced hepatitis by magnesium isoglycyrrhizinate through inhibition of neutrophil cell infiltration and oxidative damage. Mediators Inflamm. 2017;2017:1-7. doi:10.1155/2017/3526903

51. Varghese MV, Manju A, Abhilash M, et al. Oxidative stress induced by the chemotherapeutic agent arsenic trioxide. Biotech. 2014;4 (4):425-430. doi:10.1007/s13205-013-0170-0
52. Muthumani M, Prabu SM. Silibinin potentially attenuates arsenic-induced oxidative stress mediated cardiotoxicity and dyslipidemia in rats. Cardiovasc Toxicol. 2014;14(1):83-97. doi:10.1007 s12012-013-9227-x

53. Hoekstra KA, Godin DV, Kurtu J, et al. Effects of oxidant-induced injury on heme oxygenase and glutathione in cultured aortic endothelial cells from atherosclerosis-susceptible and -resistant Japanese quail. Mol Cell Biochem. 2003;254(1-2):61-71. doi:10.1023/ A:1027381110640

54. Emadi A, Gore SD. Arsenic trioxide-An old drug rediscovered. Blood Rev. 2010;24(4-5):191-199. doi:10.1016/j.blre.2010.04.001

55. Rashid S, Ali N, Nafees S, et al. Alleviation of doxorubicin-induced nephrotoxicity and hepatotoxicity by chrysin in Wistar rats. Toxicol Mech Methods. 2013;23(5):337-345. doi:10.1016/j.blre.2010.04.001

56. Rashikh A, Pillai KK, Ahmad SJ, et al. Aliskiren alleviates doxorubicin-induced nephrotoxicity by inhibiting oxidative stress and podocyte injury. J Renin Angiotensin Aldosterone Syst. 2013;14 (1):14-22. doi:10.1177/1470320312459980

57. Dabak DO, Kuloglu T, Ozercan MR. Effects of vitamin D3 (cholecalciferol) on adriamycin-induced nephrotoxicity. Ren Fail. 2009;31 (5):400-405. doi:10.1080/08860220902883020

58. Tan SN, Sim SP, Khoo AS. Potential role of oxidative stress-induced apoptosis in mediating chromosomal rearrangements in nasopharyngeal carcinoma. Cell Biosci. 2016;6:35. doi:10.1186/s13578-0160103-9

59. Akay C, Thomas Iii C, Gazitt Y. Arsenic trioxide and paclitaxel induce apoptosis by different mechanism. Cell Cycle. 2004;3 (3):322-332. doi:10.4161/cc.3.3.657

60. Calvino E, Estan MC, Simon GP, et al. Increased apoptotic efficacy of lonidamine plus arsenic trioxide combination in human leukemia cells. Reactive oxygen species generation and defensive protein kinase (MEK/ERK, Akt/mTOR) modulation. Biochem Pharmacol. 2011;82(11):1619-1629. doi:10.1016/j.bcp.2011.08.017

61. Yao P, Nussler A, Liu L, et al. Quercetin protects human hepatocytes from ethanol-derived oxidative stress by inducing heme oxygenase-1 via the MAPK/Nrf2 pathways. J Hepatol. 2007;47(2):253-261. doi:10.1016/j.jhep.2007.02.008

62. Lyu JH, Kim KH, Kim HW, et al. Dangkwisoo-san, an herbal medicinal formula, ameliorates acute lung inflammation via activation of Nrf2 and suppression of NF-kappaB. J Ethnopharmacol. 2012;140 (1):107-116. doi:10.1016/j.jep.2011.12.043

63. Wu KC, Liu J, Klaassen CD. Role of Nrf2 in preventing ethanol-induced oxidative stress and lipid accumulation. Toxicol Appl Pharmacol. 2012;262(3):321-329. doi:10.1016/j. taap.2012.05.010

64. Jaiswal AK. Nrf2 signaling in coordinated activation of antioxidant gene expression. Free Radic Biol Med. 2004;36(10):1199-1207. doi:10.1016/j.freeradbiomed.2004.02.074

65. Lee YH, Kim JH, Song $\mathrm{CH}$, et al. Ethanol extract of ganoderma lucidum augments cellular anti-oxidant defense through activation of Nrf2/HO-1. J Pharmacopuncture. 2016;19(1):59-69. doi:10.3831/ KPI.2016.19.008

66. Oyama J, Blais C, Liu X, et al. Reduced myocardial ischemia-reperfusion injury in toll-like receptor 4-deficient mice. Circulation. 2004;109 (6):784-789. doi:10.1161/01.CIR.0000112575.66565.84

67. Snyder GA, Sundberg EJ. Molecular interactions in interleukin and toll-like receptor signaling pathways. Curr Pharm Des. 2014;20 (8):1244-1258. doi:10.2174/13816128113199990069 


\section{Publish your work in this journal}

Drug Design, Development and Therapy is an international, peerreviewed open-access journal that spans the spectrum of drug design and development through to clinical applications. Clinical outcomes, patient safety, and programs for the development and effective, safe, and sustained use of medicines are a feature of the journal, which has also been accepted for indexing on PubMed Central. The manuscript management system is completely online and includes a very quick and fair peer-review system, which is all easy to use. Visit http://www. dovepress.com/testimonials.php to read real quotes from published authors. 